\title{
Laparoscopic cholecystectomy with two mini incisions: an innovative, feasible and safe technique with superior cosmetic outcomes
}

\section{Yong-fu Xu}

Taizhou Hospital of Zhejiang Province

Ai-dong Wang

Taizhou Hospital of Zhejiang Province

Zhe-ping Fang

Taizhou Hospital of Zhejiang Province

Qi-qiang Dai

Taizhou Hospital of Zhejiang Province

Zhenyu Li ( $\square$ lizhenyutz@sina.com )

Taizhou Hospital of Zhejiang Province https://orcid.org/0000-0001-6747-9296

Research article

Keywords: Laparoscopic cholecystectomy, Cosmesis, Pain, Two-incision

Posted Date: June 1st, 2020

DOI: https://doi.org/10.21203/rs.3.rs-30579/v1

License: (c) (1) This work is licensed under a Creative Commons Attribution 4.0 International License.

Read Full License 


\section{Abstract}

The conventional laparoscopic cholecystectomy (CLC) is usually performed with four incisions in a simple and safe way. Minimally invasive surgery for gallbladder disease with advantages of less pain and smaller scars, has become increasingly popular in patients. This study aimed to describe our experience in performing a new technique of two-incision laparoscopic cholecystectomy (TILC) with conventional instruments and make a comparison with CLC. In this study, forty-three prospective patients undergoing TILC and another forty-three historical cases operated by CLC were involved. The patients were examined in respect of operative time, postoperative pain, cosmesis and complications. We found that there was no significant difference in the gender, age, body mass index, bile duct damage, blood loss and days of postoperative hospital stay between TILC and CLC. The mean operation time in TILC was longer than that in CLC, but not statistically different. Significantly lower postoperative pain scores were reported in the TILC group than those in the CLC one $(p=0.019)$. The mean cosmetic satisfaction score was significantly higher in TILC group than that in CLC group $(p<0.05)$. These results confirm that TILC is a safe and feasible technique with less postoperative pain and a significant improvement in cosmesis for patients, only by using conventional instruments. It may be a good alternative to CLC in the future.

\section{Introduction}

Laparoscopic cholecystectomy (LC) is the treatment of choice for gallbladder disease(Coccolini et al. 2015; Frei et al. 1991). With enhanced experience and more advanced instrumentation, new less invasive approaches are preferred to further reduce post-operative pain, improve cosmesis and decrease recovery time in minimally invasive surgery(Bisgaard et al. 2002; Chang et al. 2020; Shaikh et al. 2017). New techniques such as natural orifice translumenal endoscopic surgery (NOTES)(Auyang et al. 2009; Gumbs et al. 2009) and single-incision laparoscopic surgery (SILS) (Castellanos et al. 2015; Yamazaki et al. 2015)have been developed in the field of cholecystectom. However, NOTES technique is still controversial as it requires a long and difficult operation process and a multidisciplinary team. In addition, there are other problems, such as unfamiliar visual approach and ethical principles(Mohan et al. 2013). Singleincision laparoscopic cholecystectomy (SILC) is also more difficult than conventional LC (CLC) because of the problems such as the triangulation difficulties, reduced intracorporeal work space, instrument and hand collision and a steep learning curve, which will greatly limit the promotion and application of SILC(Lyu et al. 2019; Sinha and Yadav 2014).

In this study, a two-incision laparoscopic cholecystectomy (TILC) was performed. The purpose of this article was to introduce our experience in performing TILC with conventional instruments, and evaluated TILC and CLC with respect to postoperative pain, cosmesis and complications such as bile duct damage, wound site inflammation and blood loss.

\section{Patients And Methods}


This study was approved by the Ethical Committee of Taizhou Hospital of Zhejiang Province. Written and informed consents were agreed by all patients. A case series of 43 consecutive patients with indications for cholecystectomy, who were treated between May 2018 and September 2018, were invited to participate in this study. Another historical series of 43 patients who underwent the standard LC technique was used as the control group. Patients with indication of cholecystectomy, regardless of whether the intervention was elective or emergent, were all included in the study. The patients with American Society of Anesthesiologists score (ASA) of more than III, or with uncontrolled medical illness, or with extensive lysis of adhesions due to previous abdominal surgeries, or those who needed exploration of biliary tract, or those who refused the invitation, were excluded. The variables such as the age, gender, body mass index (BMI), operative time, days of postoperative hospital stay, postoperative pain, cosmesis and complications were collected. Postoperative pain was evaluated by using a visual analogue scale (VAS) at the postoperative 6th hour (VAS-6) and 24th hour (VAS-24)(Wewers and Lowe 1990). The patients were required to score on a scale from 0 (no pain) to 10 (the worst pain imaginable). Cosmetic outcome was assessed according to Photo Series Questionnaire (PSQ), on a scale from 1 (the worst satisfaction) to 10 (the best satisfaction) on postoperative day 7(Dunker et al. 1998).

\section{Operative technique}

In TILC technique, the patient was placed in the dorsal decubitus position and underwent general anesthesia. The surgeon and assistant stood on the left of the patient. A longitudinal incision of about 12 $\mathrm{mm}$ was made in umbilicus. Pneumoperitoneum was created with a veress needle in the same manner as CLC. The first 5-mm port (P1) was placed into the umbilical incision and $5 \mathrm{~mm} 30^{\circ}$ laparoscope (Olympus) was inserted. Then, the patient was placed in the reverse Trendelenburg position and tilted towards the surgeon to fully expose the gallbladder. Another incision was made at the epigastrium, just below the xiphoid, to allow the insertion of a second $5 \mathrm{~mm}$ port (P2). The third 5-mm port (P3) was placed at the corner in the right end of the umbilical incision beside P1 under direct vision by placing the laparoscope through P2. The 5-mm laparoscope was placed on P1, and a grasping clamp was on P3 to hold and manipulate the gallbladder (Fig.1 a). The dissection forceps, hook and clip applier were freely used on P2, and a standard cholecystectomy was performed (Fig.1 b and c). Finally, the laparoscope was shifted to $\mathrm{P} 2$, and both $5 \mathrm{~mm}$ ports in the umbilical incision were removed and replaced by a 10-mm port. The gallbladder was then removed through the umbilical incision with an endopouch (Fig. $1 \mathrm{~d}$ ).

\section{Statistical analysis}

Statistical analysis was performed with SPSS 22.0 software (SPSS, Chicago, IL, USA). Chi-square or Fisher's exact was applied to compare the distribution of nominal variables between two groups. Student's t test was applied to determine the differences of those normal continuous variables and Mann-Whitney test was used for the asymmetrically distributed variables. $P<0.05$ was considered to be significant.

\section{Results}


A total of 46 patients underwent TILC, and three were excluded from the study. One of those was diagnosed with pancreatitis and another two patients needed exploration of the biliary ducts. Another 43 consecutive patients who previously received standard LC technique, were used as the control group. All the cases were operated on by the same surgeon.

The patient characteristics of two groups are summarized in Table 1. No significant difference was observed in the gender, age and BMI. The mean operation time was higher in TILC (49.19 \pm 8.59 minutes) than that in CLC group (47.79 \pm 9.15 minutes), but not statistically different.

The data related to complications are shown in Table 2. One patient was transferred to open cholecystectomy in CLC group. There was no bile duct damage or massive haemorrhage in any case. The mean amount of intra-operative blood loss was similar between both two groups. Although the wound site inflammation was developed in two patients of the TILC group, which was treated with dressing change and conservative monitoring and without any further intervention, there was no statistical difference in the incidence between two types of laparoscopy.

Although the VAS- 6 scores of the two groups were not statistically significant, the CLC group scored higher. The VAS-24 scores were significantly lower in TILC group than those in CLC group $(2.16 \pm 0.92$ vs $2.65 \pm 0.97, p=0.051)$. In the evaluation of cosmetic satisfaction, the PSQ scores of the TILC cases were higher than those of the CLC group, and there was a statistically significant difference between the groups $(p \leq 0.001)$ as shown in Table 3.

\section{Discussion}

Minimally invasive surgery for gallbladder disease has advantages of less pain, smaller scars, shorter length of hospital stay and quicker return to normal activities, which has become increasingly popular in patients(Bignell et al. 2013; Bisgaard et al. 2002; Sinagra et al. 2018). Although several studies have revealed the efficacy of SILC, its increased risks of pain, bile duct injury and port-site hernia formation with a larger umbilical incision and prolonged operative time, and the need for specialty ports and instruments have raised conflicting concerns(Arezzo et al. 2018; Hoyuela et al. 2019; Lee et al. 2019; Lim et al. 2017). In this study, a TILC technique was described that only needs conventional instruments. All patients were operated on with a 5-mm laparoscope, which was placed in the umbilical incision and provided visual field and image exactly the same as CLC. The positioning of one forceps in the umbilicus and another in the epigastrium allowed for optimal triangulation. Hand collision was the biggest challenge during TILC. Based on our practice and understanding, the way of two instruments in the same incision working as ' $X$ ' creates only one axis of rotation between them to reduce collision. In such a way, surgeons can work in a very similar manner to CLC, which will result in the same safety care.

The main benefits of TILC include better cosmesis and reduced postoperative pain. The date from this study showed that the pain scores (VAS-24) were significantly lower in TILC group than those in CLC group. The reduction of incisional trauma and total incision number may account for the relieved postoperative pain in patients who received TILC. The cosmetic advantages of such 'scarless' operation 
are very important for patients. TILC showed higher cosmetic satisfaction score because of the reduced incision number and an anatomically concealed incision within the umbilical scar. The most important criteria to evaluate the outcomes are the morbidity and complications, and no significant difference was observed in common bile duct injury and bleeding between both groups, indicating that TILC is safe and feasible.

After reviewing similar techniques or researches, some other methods of minimally invasive cholecystectomy were also identified, but not the same as this study. In a study by Alireza Tavassoli, compared with the classic four-port LC, TILC is more effective in postoperative pain and cosmesis, which is similar to the results in this study. However, it is important to note that their technique is somehow different. The first $1 \mathrm{~cm}$ incision was made in umbilicus and fascia, and two $5 \mathrm{~mm}$ ports were inserted. Then, another $1 \mathrm{~cm}$ incision was made just above the pubic hair in the lower abdomen extending right to the middle, and a $10 \mathrm{~mm}$ port was placed for inserting a 10-mm laparoscope. Therefore, two instruments in umbilicus cannot form a good triangulation, which will greatly increase the difficulty of the operation(Tavassoli and Noorshafiee 2018). In another article by Antonio et al. TILC technique has been successfully performed but the port location is different from this study, showing that the technique is safe and feasible(D'Antonio et al. 2013). Lai et al. also confirmed that TILC is a safe alternative to CLC for pediatric gallbladder disease. But an especial instrument (2-mm endoscopic grasper) was needed during his operation and obese patients were more likely to require additional ports(Lai et al. 2017).

\section{Conclusion}

In summary, this study demonstrated that TILC is safe and feasible, and exhibits less postoperative pain and a remarkable improvement in cosmesis for patients. It allows for the only usage of the same instruments as CLC, without increasing the costs. If two laparoscopic techniques are equivalent with respects to the safety, availability, cost, and learning curve, TILC is possible to play essential role for the patients to have more choices in the future.

\section{Declarations}

Funding: This study was supported by grants from the National Natural Science Foundation of China (Grant No. 81872237), the Science Technology Program of Zhejiang Province on the Scientific Research Project (Grant No. GF19H160059, Y17H160289 and LQ18H160028)『Zhejiang Provincial Health Department Project (Grant No. 2016KYA191) and the Science Technology Program of Taizhou on the Scientific Research Project (Grant No.1901ky06).

Conflicts of interest/Competing interests: Not applicable

Ethics approval: The study protocol was approved by the Ethical Committee of Taizhou Hospital of Zhejiang Province. 
Consent to participate: Written informed consent was obtained from all the patients. The study was performed in accordance with the Declaration of Helsinki.

Consent for publication: We all agreed to submit our manuscript to The SCIENCE OF NATURE.

Availability of data and material (data transparency) : All the data and material are available.

\section{Conflicts of interest}

There are no conflicts of interest.

\section{References}

Arezzo A, Passera R, Forcignanò E, Rapetti L, Cirocchi R, Morino M (2018) Single-incision laparoscopic cholecystectomy is responsible for increased adverse events: results of a meta-analysis of randomized controlled trials Surgical endoscopy 32:3739-3753 doi:10.1007/s00464-018-6143-y

Auyang ED, Hungness ES, Vaziri K, Martin JA, Soper NJ (2009) Natural orifice translumenal endoscopic surgery (NOTES): dissection for the critical view of safety during transcolonic cholecystectomy Surgical endoscopy 23:1117-1118 doi:10.1007/s00464-009-0407-5

Bignell M, Lewis MP, Cheong EC, Rhodes M (2013) A prospective, randomized, single-blind trial of 5-mm versus 3-mm ports for laparoscopic cholecystectomy: is smaller better? Surgical endoscopy 27:36163621 doi:10.1007/s00464-013-2933-4

Bisgaard T, Klarskov B, Trap R, Kehlet H, Rosenberg J (2002) Microlaparoscopic vs conventional laparoscopic cholecystectomy: a prospective randomized double-blind trial Surgical endoscopy 16:458464 doi:10.1007/s00464-001-9026-5

Castellanos A, Fazendin J, Panait L (2015) Single-incision laparoscopic cholecystectomy Clinical liver disease 5:5-7 doi:10.1002/cld.431

Chang K, Gokcal F, Kudsi OY (2020) Robotic Biliary Surgery The Surgical clinics of North America 100:283-302 doi:10.1016/j.suc.2019.12.002

Coccolini F et al. (2015) Open versus laparoscopic cholecystectomy in acute cholecystitis. Systematic review and meta-analysis International journal of surgery (London, England) 18:196-204 doi:10.1016/j.ijsu.2015.04.083

D'Antonio D, Franzato B, Fusco G, Ruperto M, Dal Pozzo A (2013) Double incision laparoscopic cholecystectomy (DILC) with routinary intra-operative cholangiography (IOC) : less trauma, same safety. Report on 30 consecutive non-selected cases Updates in surgery 65:109-114 doi:10.1007/s13304-0130200-9 
Dunker MS, Stiggelbout AM, van Hogezand RA, Ringers J, Griffioen G, Bemelman WA (1998) Cosmesis and body image after laparoscopic-assisted and open ileocolic resection for Crohn's disease Surgical endoscopy 12:1334-1340 doi:10.1007/s004649900851

Frei E et al. (1991) [Laparoscopic cholecystectomy-results of the first 100 cases] Helvetica chirurgica acta $58: 153-158$

Gumbs AA, Fowler D, Milone L, Evanko JC, Ude AO, Stevens P, Bessler M (2009) Transvaginal natural orifice translumenal endoscopic surgery cholecystectomy: early evolution of the technique Annals of surgery 249:908-912 doi:10.1097/SLA.0b013e3181a802e2

Hoyuela C, Juvany M, Guillaumes S, Ardid J, Trias M, Bachero I, Martrat A (2019) Long-term incisional hernia rate after single-incision laparoscopic cholecystectomy is significantly higher than that after standard three-port laparoscopy: a cohort study Hernia : the journal of hernias and abdominal wall surgery 23:1205-1213 doi:10.1007/s10029-019-01969-x

Lai SW, Rothenberg SS, Shipman KE, Kay SM, Slater BJ (2017) Two-Incision Laparoscopic Cholecystectomy in Children Journal of laparoendoscopic \& advanced surgical techniques Part A 27:306310 doi:10.1089/lap.2016.0221

Lee SR, Kim HO, Shin JH (2019) Clinical outcomes of single-incision robotic cholecystectomy versus conventional 3-port laparoscopic cholecystectomy Canadian journal of surgery Journal canadien de chirurgie 62:52-56 doi:10.1503/cjs.000118

Lim C et al. (2017) Single-incision robotic cholecystectomy is associated with a high rate of trocar-site infection The international journal of medical robotics + computer assisted surgery : MRCAS 13 doi:10.1002/rcs.1856

Lyu Y, Cheng Y, Wang B, Zhao S, Chen L (2019) Single-incision versus conventional multiport laparoscopic cholecystectomy: a current meta-analysis of randomized controlled trials Surgical endoscopy doi:10.1007/s00464-019-07198-8

Mohan HM, O'Riordan JM, Winter DC (2013) Natural-orifice translumenal endoscopic surgery (NOTES): minimally invasive evolution or revolution? Surgical laparoscopy, endoscopy \& percutaneous techniques 23:244-250 doi:10.1097/SLE.0b013e31828b8b7b

Shaikh HR, Abbas A, Aleem S, Lakhani MR (2017) Is mini-laparoscopic cholecystectomy any better than the gold standard?: A comparative study Journal of minimal access surgery 13:42-46 doi:10.4103/09729941.181368

Sinagra E et al. (2018) Minimally invasive surgical approach for radicalization of incidental postcholecystectomy gallbladder carcinoma: safety, feasibility and outcomes Minim Invasive Ther Allied Technol 27:217-220 doi:10.1080/13645706.2017.1410489 
Sinha R, Yadav AS (2014) Transumbilical single incision laparoscopic cholecystectomy with conventional instruments: A continuing study Journal of minimal access surgery 10:175-179 doi:10.4103/09729941.141502

Tavassoli A, Noorshafiee S (2018) Laparoscopic cholecystectomy with two mini cosmetic incisions Updates in surgery 70:73-76 doi:10.1007/s13304-017-0504-2

Wewers ME, Lowe NK (1990) A critical review of visual analogue scales in the measurement of clinical phenomena Research in nursing \& health 13:227-236 doi:10.1002/nur.4770130405

Yamazaki M, Yasuda H, Koda K (2015) Single-incision laparoscopic cholecystectomy: a systematic review of methodology and outcomes Surgery today 45:537-548 doi:10.1007/s00595-014-0908-2

\section{Tables}

Table 『. Patient characteristics.

\begin{tabular}{llll} 
Variable & \multicolumn{2}{l}{ Group } & Pvalue \\
\cline { 2 - 4 } & TILC & CLC & \\
\hline Gender (M/F) & $18 / 25$ & $17 / 26$ & 0.826 \\
\hline Age (year) & $48.44 \pm 13.25$ & $49.74 \pm 11.75$ & 0.631 \\
\hline BMI (kg/m2) & $23.90 \pm 3.34$ & $24.44 \pm 4.18$ & 0.508 \\
\hline Operation time(min) & $49.19 \pm 8.59$ & $47.79 \pm 9.15$ & 0.468
\end{tabular}

TILC, two-incision laparoscopic cholecystectomy

CLC, conventional laparoscopic cholecystectomy

Table $\llbracket$. Complication and operative data. 


\begin{tabular}{llll} 
Variable & Group & & $P$ value \\
\cline { 2 - 4 } & TILC & CLC & \\
\hline Blood loss $(\mathrm{ml})$ & $11.86 \pm 5.35$ & $12.67 \pm 3.83$ & 0.420 \\
\hline Bile duct damage & 0 & 0 & 1 \\
\hline Conversion to open & 0 & 1 & 1.000 \\
\hline Wound site inflammation & 2 & 0 & 0.494
\end{tabular}

TILC,two-incision laparoscopic cholecystectomy

CLC, conventional laparoscopic cholecystectomy

Table \. Postoperative data.

\begin{tabular}{|c|c|c|c|}
\hline \multirow[t]{2}{*}{ Variable } & \multicolumn{2}{|l|}{ Group } & \multirow[t]{2}{*}{$P$ value } \\
\hline & TILC & CLC & \\
\hline VAS-6 & $3.93 \pm 0.91$ & $4.16 \pm 0.97$ & 0.256 \\
\hline VAS-24 & $2.16 \pm 0.92$ & $2.65 \pm 0.97$ & $0.019 *$ \\
\hline Cosmetic satisfaction & $8.86 \pm 0.86$ & $7.93 \pm 1.24$ & $0.000 *$ \\
\hline Days of postoperative hospital stay & $1.26 \pm 0.54$ & $1.35 \pm 0.65$ & 0.472 \\
\hline \multicolumn{4}{|c|}{ TILC,two-incision laparoscopic cholecystectomy } \\
\hline \multicolumn{4}{|c|}{ CLC, conventional laparoscopic cholecystectomy } \\
\hline * $p<0.05$ & & & \\
\hline
\end{tabular}

Figures 
(a)

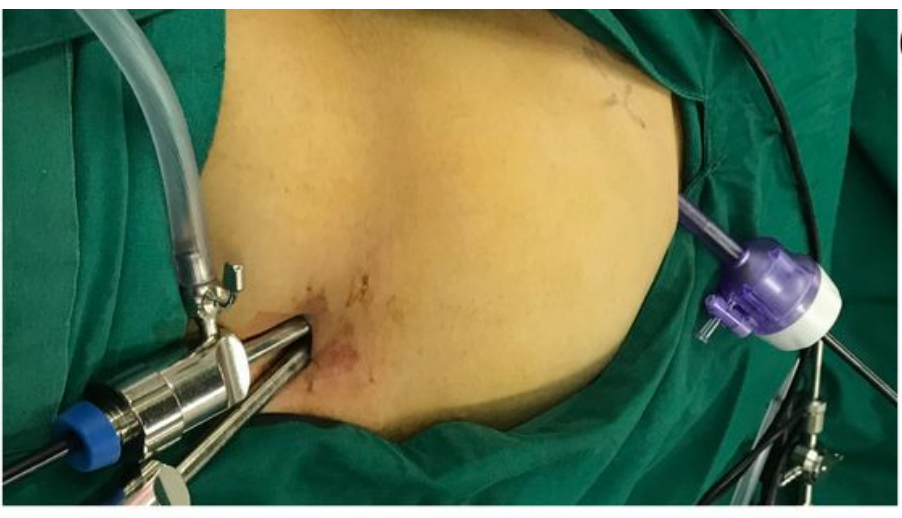

(c)

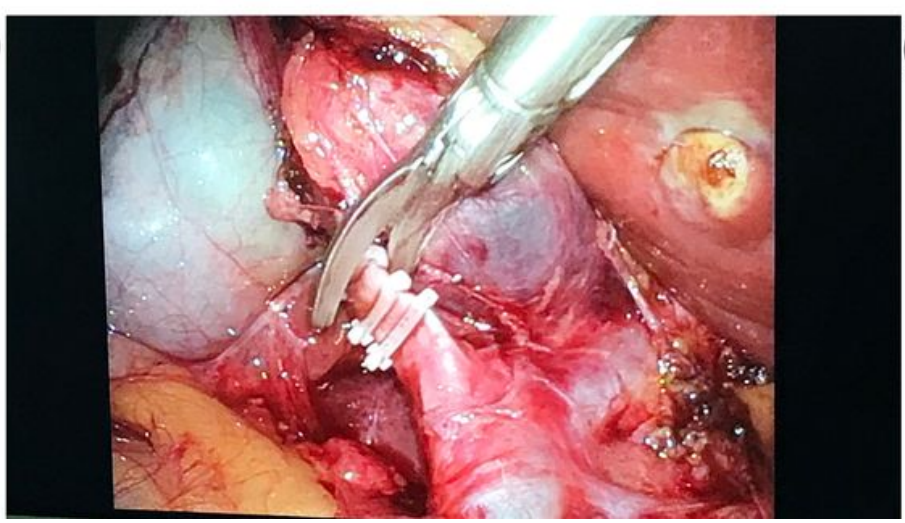

(b)

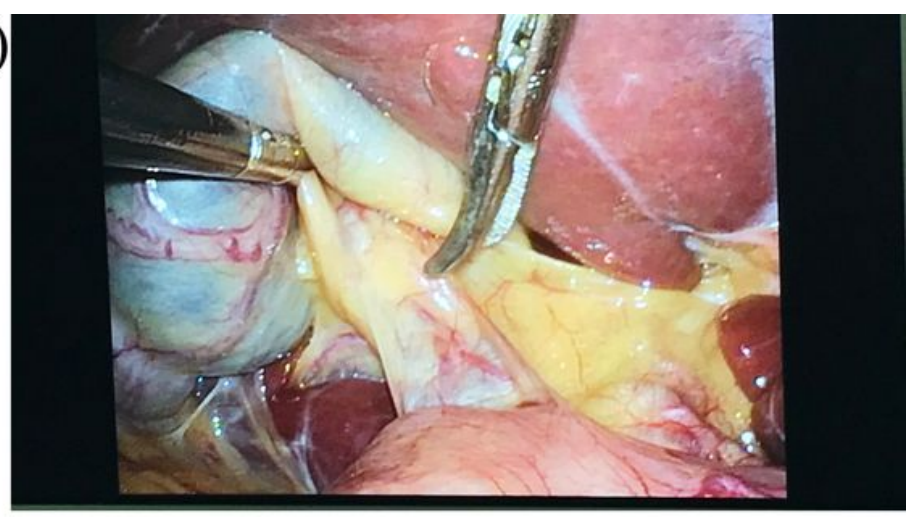

(d)

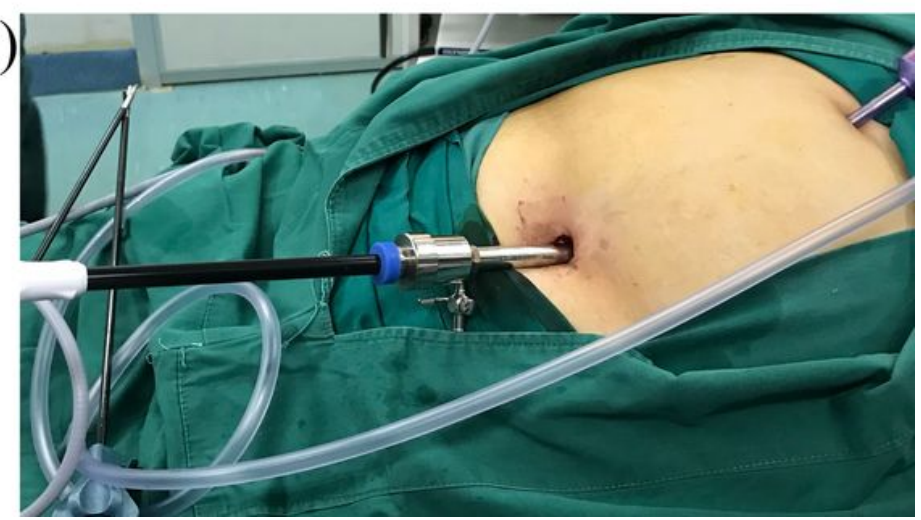

Figure 1

(a) Arrangement of instruments in two-incision laparoscopic cholecystectomy (TILC). (b) Calot's triangle of gallbladder. (c) Cystic duct clipping with gallbladder in traction. (d)Retrieving gallbladder through the umbilical incision with an endopouch. 